\title{
Optical Insights into Enhancement of Solar Cell Performance Based on Porous Silicon Surfaces
}

\author{
Asmiet Ramizy ${ }^{1,3}$, Y. Al-Douri' ${ }^{2}$, Khalid Omar ${ }^{1}$ and Z. Hassan ${ }^{1}$ \\ ${ }^{1}$ Nano-Optoelectronics Research and Technology Laboratory, \\ School of Physics, Universiti Sains Malaysia, Penang, \\ 2Institute of Nano Electronic Engineering, University Malaysia Perlis \\ ${ }^{3}$ University of Anbar-collage of sciences-physics department, \\ 1,2 Malaysia \\ ${ }^{3} \operatorname{raq}$
}

\section{Introduction}

The amount of light reflection from the surface is the main obstacle in efficient solar cell performance because reflection is related to the refractive index of the material. For instance, the silicon ( $\mathrm{Si}$ ) refractive index is 3.5 , (which can rise by up to $35 \%$ ), which prevents an electron-hole pair from being generated and could reduce the efficiency of photovoltaic converters. Antireflection coatings ARC are able to reduce surface reflection, increase conversion efficiency, extend the life of converters, and improve the electrophysical and characterization of photovoltaic converters [1].

Porous Si (PS) is attractive in solar cell applications because of its efficient ARC and other properties such as band gap broadening, wide absorption spectrum, and optical transmission range (700-1000 nm). Furthermore, PS can also be used for surface passivation and texturization [2-6]. The potential advantages of PS as an ARC for solar cells include surface passivation and removal of the dead-layer diffused region. Moreover, PS is able to convert higher energy solar radiation into spectrum light, which is absorbed more efficiently into bulk Si [7].

The vibrations, electronic, and optical properties of PS have been studied using various experimental techniques. Of these, the electrochemical etching process is a promising technique for fabricating PS [8-11]. According to the quantum confinement model, a heterojunction can be formed between the Si substrate and porous layers because the latter has a wider band gap (1.8-2.2 eV) compared with crystalline Si (c-Si) [12].

Recently, Ben Rabha and Bessais [13] used chemical vapor etching to perform the front PS layer and buried metallic contacts of multicrystalline silicon solar cells to reduce reflectivity to $8 \%$ in the 450-950 nm wavelength range, yielding a simple and low-cost technology with $12 \%$ conversion efficiency. Yae et al. [14] deposited fine platinum $(\mathrm{Pt})$ particles on multicrystalline $\mathrm{n}$ $\mathrm{Si}$ wafers by electroless displacement reaction in a hexachloroplatinic acid solution containing HF. The reflectance of the wafers was reduced from $30 \%$ to $6 \%$ by the formation of porous layer. Brendel [15] performed electrochemical etching of PS layer into the substrate based on homoepitaxial growth of monocrystalline Si films, yielding a module efficiency of $10 \%$.

The present work aims to investigate the effect of PS on performance of Si solar cells. Optical properties such as refractive index and optical dielectric constant are investigated. 
Enhancing solar cell efficiency can be realized by manipulating back reflected mirrors, and the results are promising for solar cell manufacturing because of the simplicity, lower-cost technology, and suitability for mass production of the method.

\section{Experimental procedure}

\subsection{PS Structure formation}

An n-type Si wafer with a dimension of $1 \mathrm{~cm} \times 1 \mathrm{~cm} \times 283 \mu \mathrm{m}$, (111) orientation, resistivity of 0.75 S.cm, and doping concentration of $1.8 \times 1017 \times \mathrm{cm}^{-3}$ was etched through an electrochemical process to produce the porous structure. The wafer was placed in an electrolyte solution [hydrofluoric acid (HF): Ethanol, 1:4] with a current density of 60 $\mathrm{mA} / \mathrm{cm}^{2}$ at an etching time of $30 \mathrm{~min}$. To produce solar cells on both sides of the PS, the PS wafer was fabricated by electrochemical etching at the current density of $60 \mathrm{~mA} / \mathrm{cm}^{2}$ for 15 min on each side.

Before the etching process, the Si substrate was cleaned using the Radio Corporation of America (RCA) method to remove the oxide layer, and then immersed in HF acid to remove the native oxide. The electrochemical cell is made of Teflon and has a circular aperture with a radius of $0.4 \mathrm{~cm}$, with the silicon wafer sealed below. The cell consists of a two-electrode system with the Si wafer as the anode and platinum as the cathode, as shown in Fig. 1 . The process was carried out at room temperature. After etching, all samples were rinsed with ethanol and air-dried. Surface morphology and structural properties of the samples under treatment were characterized using scanning electron microscopy (SEM). The PS optical reflectance was obtained using an optical reflectometer (Filmetrics F20) with an integrating sphere. Fourier transform infrared spectroscopy (FTIR) of the PS samples was performed, and photoluminescence (PL) spectroscopy was performed at room temperature using HeCd laser $(\lambda=325 \mathrm{~nm})$.

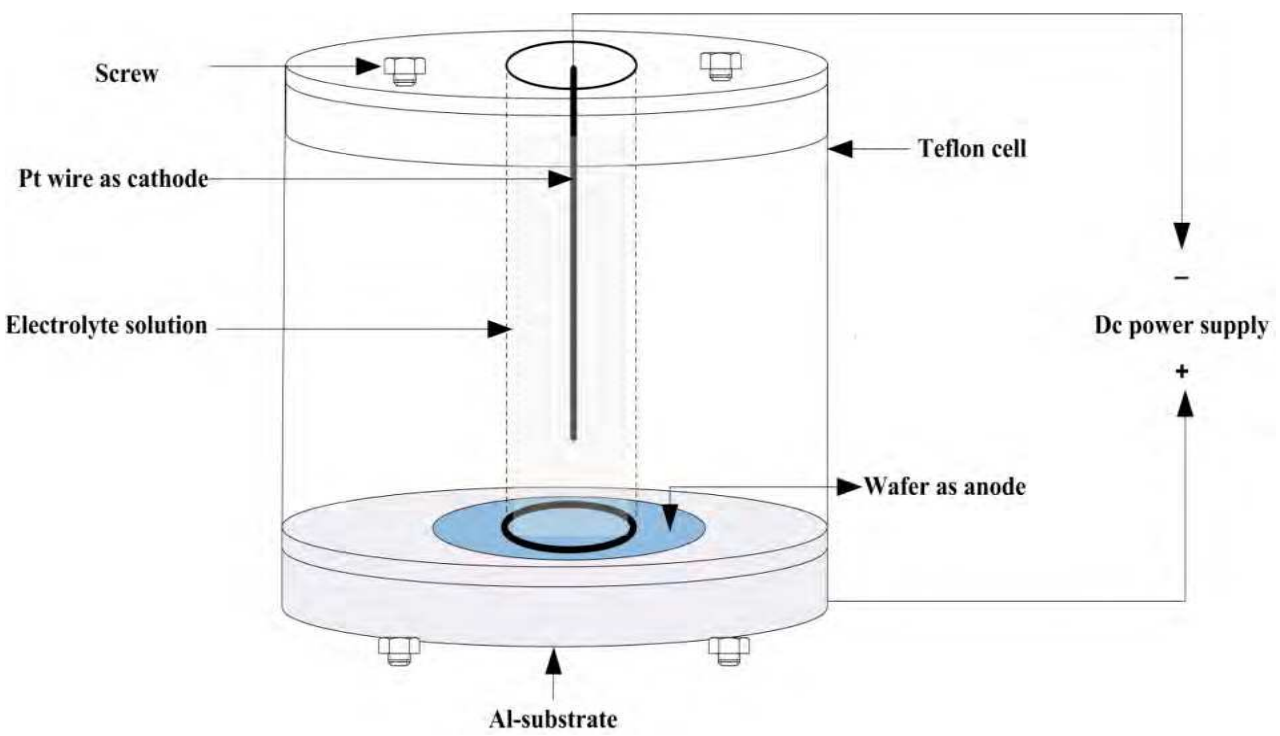

Fig. 1. Schematic of the electrochemical etching setup 


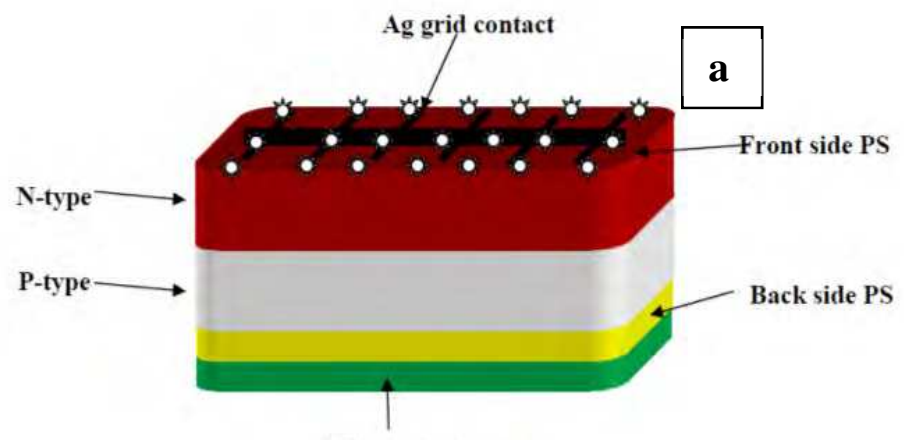

Al back contact
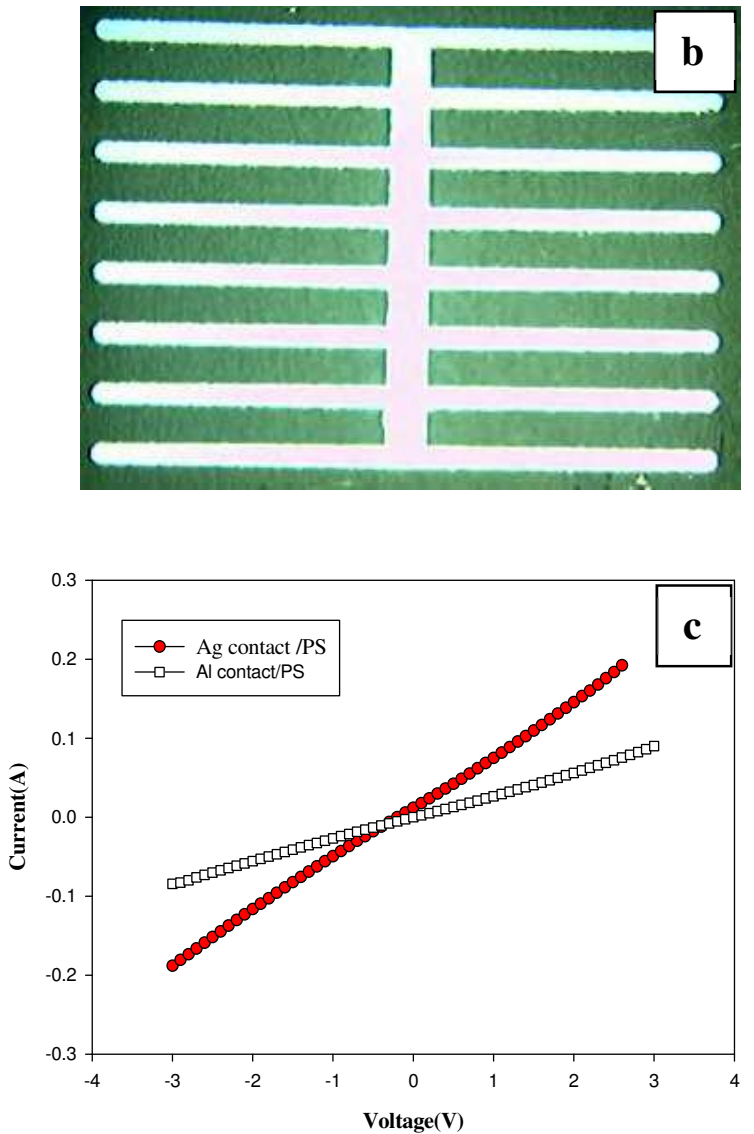

Fig. 2. Solar cells setup (a) p-n junction layers, (b) metal mask, and (c) contact I-V characterization 


\subsection{Solar cell fabrication}

After the (RCA) cleaning and oxidation, the silicon wafer underwent spin-coating. A liquid containing photoresistant material was placed at the center of the wafer. The spinning process was conducted at room temperature at the speed of $300 \mathrm{rpm}$ for $20 \mathrm{~s}$. After spin-coating, the wafer was placed back into the furnace for $20 \mathrm{~min}$ at $200^{\circ} \mathrm{C}$ to remove moisture. The mask was designed by the photoplotter technique placed directly above the sample and exposed to UVlight for $25 \mathrm{~s}$ to form a patterned coating on the surface. Doping diffusion was carried out using a tube furnace at the temperature of $1100{ }^{\circ} \mathrm{C}$ for $60 \mathrm{~min}$ using $\mathrm{N}_{2}$ flow gas. The top surface area of the wafer was doped with boron to be P-type. Prior to the contact evaporating process, the oxidation layer was removed using an etching solution of $\mathrm{NH}_{4} \mathrm{~F}: \mathrm{H}_{2} \mathrm{O}$, and then mixed with HF with a mole ratio of 1:7. Aluminum evaporation was used for the back metal contact, whereas silver was used for front metallization. Figure 1 shows the setup of the solar cells. Contact annealing was performed at $400{ }^{\circ} \mathrm{C}$ for $20 \mathrm{~min}$ to pledge ohmic contact (see Fig. 1 ), as well as to improve the contact properties. A back reflected mirror with reflectivity $>89 \%$ was used to enhance solar cell efficiency. The structure of the PS solar cells consists of a metal mask contact of grid pattern with a finger width of $300 \mu \mathrm{m}$ and finger spacing of $600 \mu \mathrm{m}$.

The fabricated device was analyzed using current-voltage (I-V) measurement, with the lens placed under solar simulator illumination. A solar cell using unetched c-Si was fabricated under the same conditions for comparison.
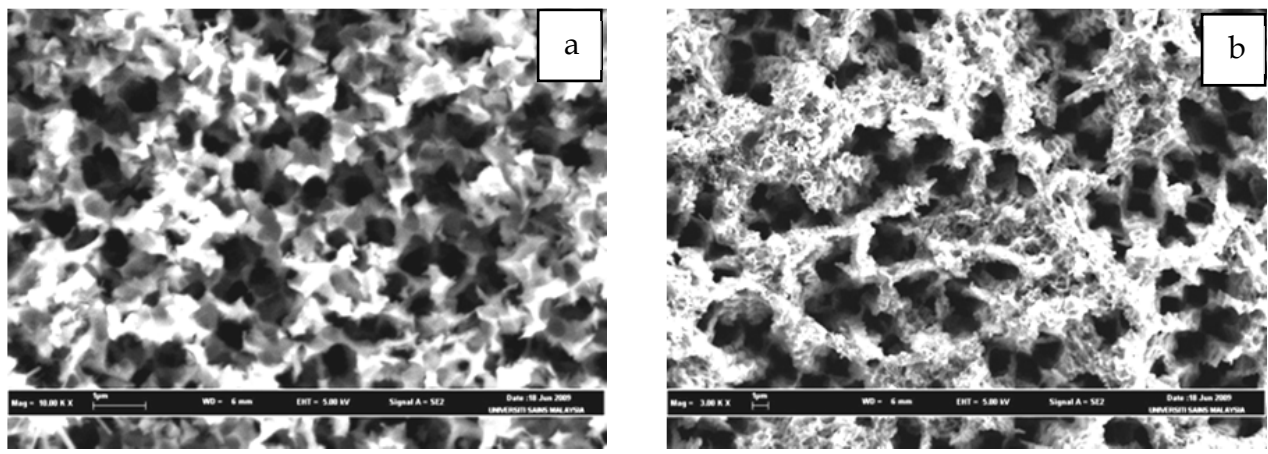

Fig. 3. SEM images of PS formed on (a) N (100), (b) P (100)
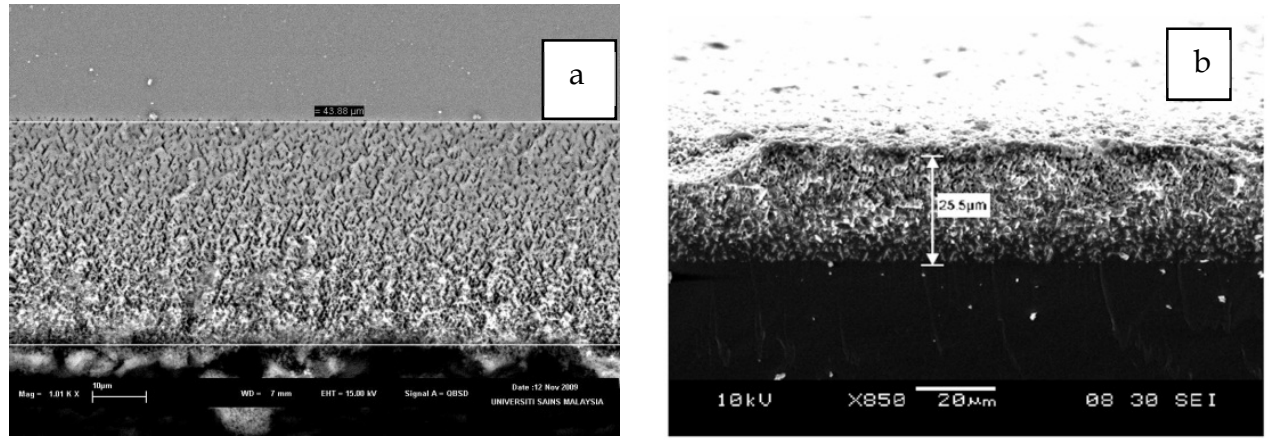

Fig. 4. Cross-sectional SEM images of PS on (a) both sides of the c-Si wafer and (b) on the 47 polished front 


\section{Effect of doping-type of porous on silicon solar cell performance}

The SEM images in Figs. 3 (a) and (b) reveal the grains of the surface texturing with similar grain geometry, which is caused by the isotropic character of the HF/ethanol etching and the optimal conditions for current density and etching time. Moreover, similar morphology is apparent in the SEM images of all etched surfaces. The depth of porosity increased with the N-type silicon wafers compared with P-type, as shown in Figs. 4 (a) and (b), which may be due the abundance of electron-hole pair charge carriers that lead to extra chemical interaction between the electrolyte solution and the surface of the silicon wafer, resulting in the formation of PS.

The surface reflections of PS N (100) show a reduction of incoming light reflection and an increase in capturing the light of the wide wavelength range compared with PS P (100) reflection, as illustrated in Fig. 5. This caused the N (100) surface formed to be preferentially dissolved because of the preferred pore tips. However, the P (100) surface is most effective for preferred pore walls during the etching processing.

Figure 6 reveals the Raman spectra of bulk silicon, which show a sharp line in the spectra with FWHM of $3.5 \mathrm{~cm}^{-1}$ shifted by $522 \mathrm{~cm}^{-1}$ relative to the laser line incident. However, the PS spectra became broader relative to the $517 \mathrm{~cm}-1$ sharp with FWHM of $8.2 \mathrm{~cm}^{-1}$ in PS P (100) and shifted to $510 \mathrm{~cm}^{-1}$ with (FWHM) of $17.3 \mathrm{~cm}^{-1}$ in PS N (100), which is attributed to the quantum confinement effect on electronic wave function of silicon nanocrystals [16]

Figure 7 shows the PL spectrum of PS P (100) at $698.9 \mathrm{~nm}(1.77 \mathrm{eV})$ with FWHM of about 140 nm. In PS N (100), PL at $670.35 \mathrm{~nm}(1.82 \mathrm{eV})$ with FWHM of $123 \mathrm{~nm}$ is evident. The PL output intensity in the N-type becomes stronger because of an increase in the number of emitted photons on the porous surface. The peak shift increase with N-type PS compared with P-type wafers, which can be attributed to the abundance of charge carriers, enhances the spontaneous etching rate of silicon. The particles are confined into a lower dimension, leading to higher efficiency. Without these charge carriers, the etching process substantially slows down.

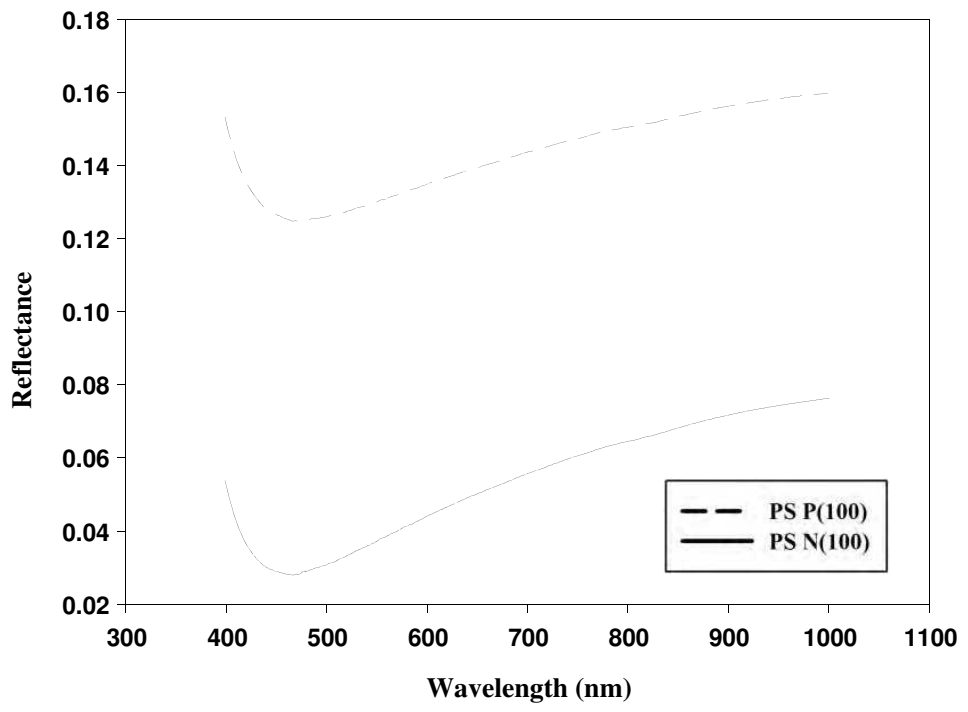

Fig. 5. Reflectance spectra for PS N (100) and P (100) 


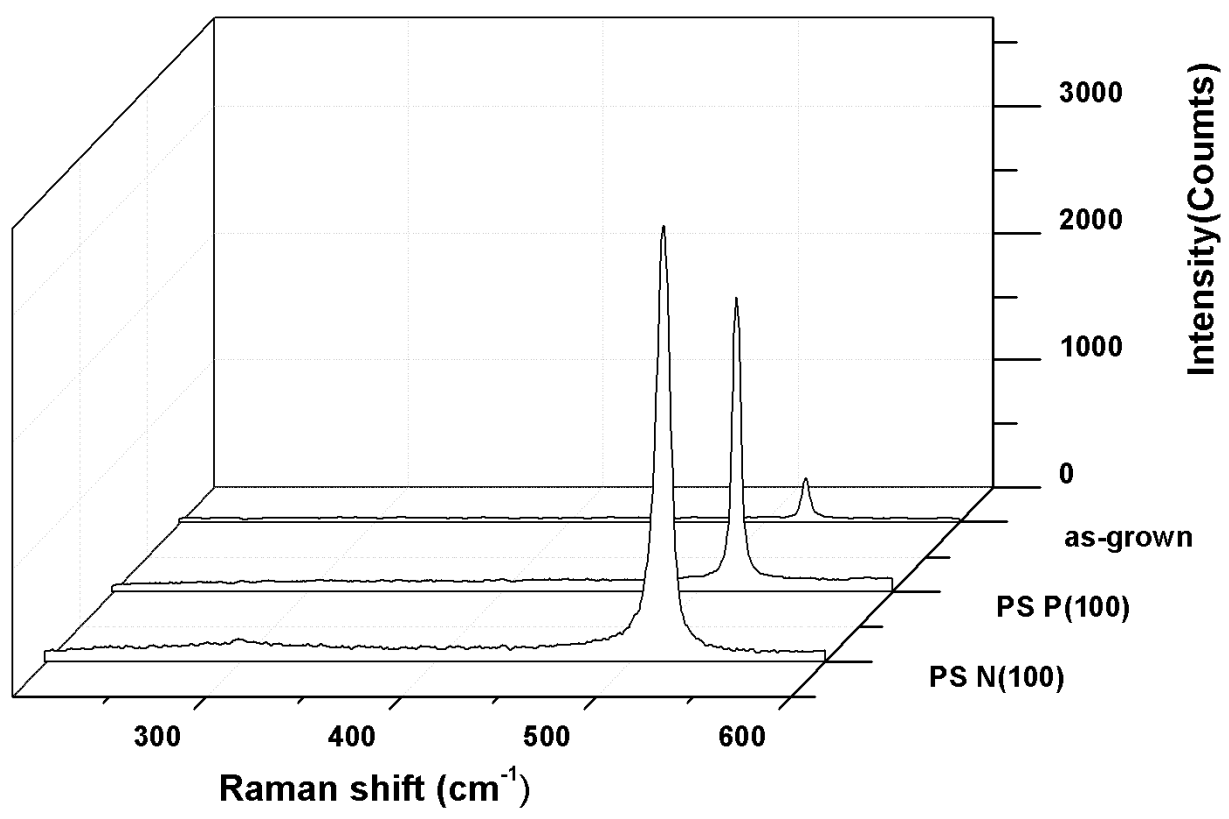

Fig. 6. Raman spectra of PS prepared by electrochemical etching

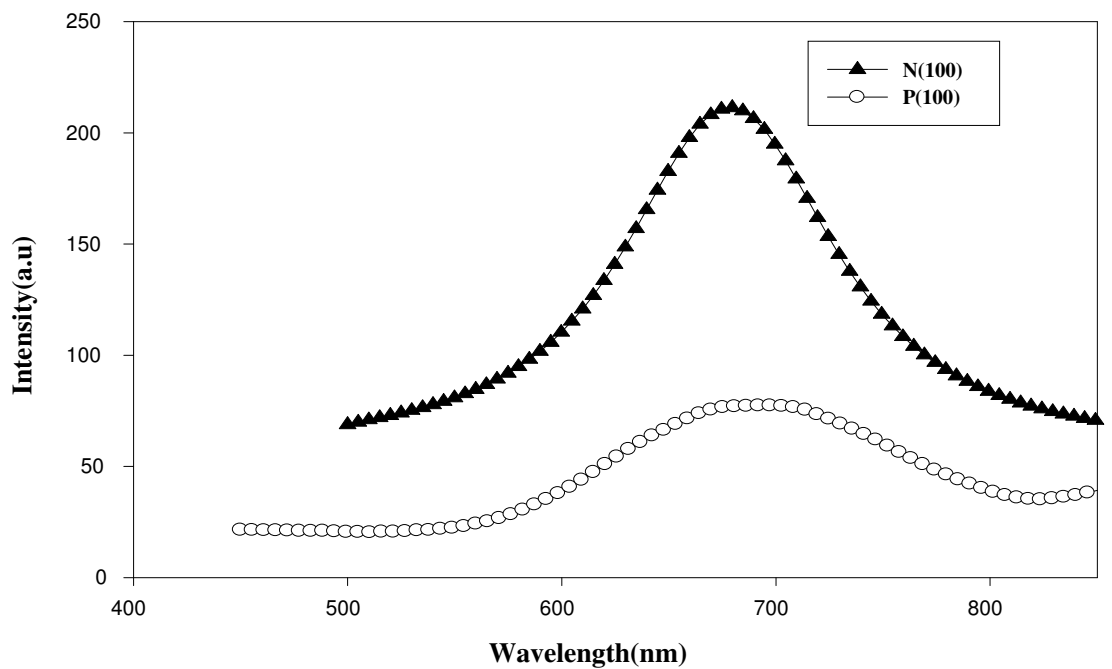

Fig. 7. PL spectra of PS prepared by electrochemical etching

The experimental data in Fig. 8 and Table 1 show that the solar cell with PS N (100) increases the short-circuit current to 12.2 , open current voltage to 0.36 , and conversation efficiency to 10.85 in comparison to the solar cell fabricated with PS P (100). 


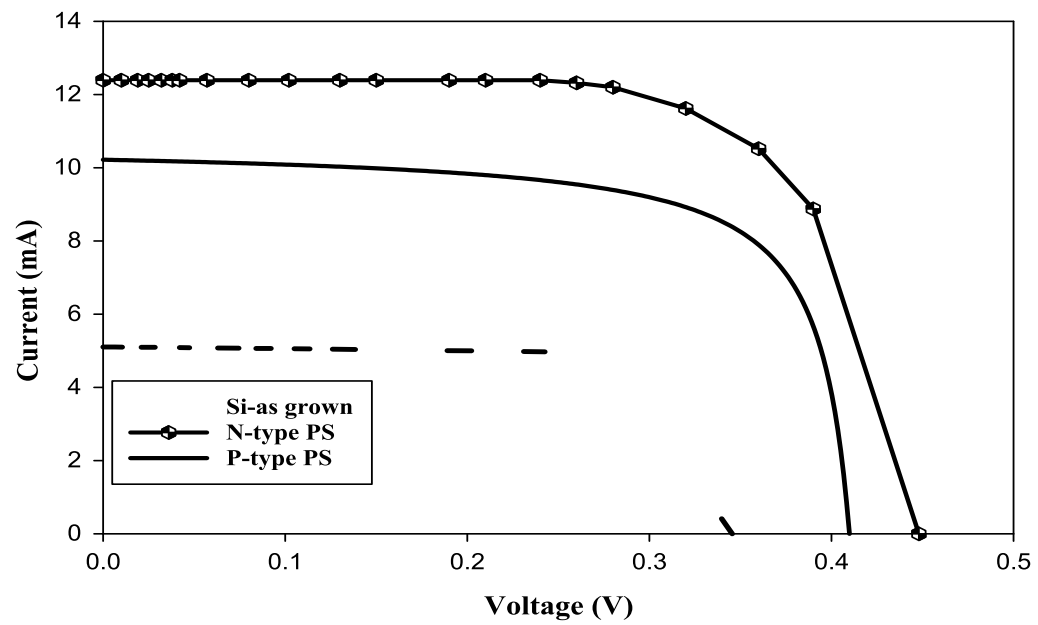

Fig. 8. Current-voltage characteristics of PS N (100) and P (100) solar cells

\begin{tabular}{|c|c|c|c|c|c|c|}
\hline Samples & $\operatorname{Vm}(\mathrm{V})$ & $\operatorname{Im}(\mathrm{mA})$ & $\operatorname{Voc}(\mathrm{V})$ & $\operatorname{Isc}(\mathrm{mA})$ & FF & Efficiency $(\eta)$ \\
\hline Si as- grown & 0.26 & 5.09 & 0.34 & 5.1 & 0.77 & $3.34 \%$ \\
\hline P-type PS & 0.33 & 10.03 & 0.41 & 10.2 & 0.81 & $8.4 \%$ \\
\hline N-type PS & 0.36 & 12.1 & 0.42 & 12.2 & 0.85 & $10.85 \%$ \\
\hline
\end{tabular}

Table 1. Fill factor (FF) and efficiency $(\eta)$ of PS N (100) and P (100)

\section{New optical features to enhance solar cell performance based on porous silicon surfaces}

The efficiency of photovoltaic energy conversion must be enhanced to reduce the cost of solar cell modules for energy generation. In this process, photons from solar radiation fall on a solar cell that generate electron and hole pairs, which are then collected at the contact points. However, a drawback of solar photovoltaic energy conversion is that most of the semiconducting materials used are sensitive only to a part of the solar radiation spectrum.

Figure 9a shows cross-sectional SEM images of chemically treated samples. These images show that the thickness is uniform throughout the obtained porous layer, indicating that the etching process forms a uniform porous density layer on the surface. The SEM images in Figs. 9 (b) and (c) illustrate the treated surface with similar grain geometry because of the isotropic character of HF/ethanol etching and the optimal conditions of the current density and etching time. The images show that the entire surface of the sample is etched, and that most of the pores are spherical. In addition to the short-branched pores, the porous surface formed on the front polished side has discrete pores. In contrast, the PS surface formed on the unpolished backside is shaped in small pores, which could be attributed to an increase in surface roughness for the unpolished backside that is proportional to the etching parameter. 


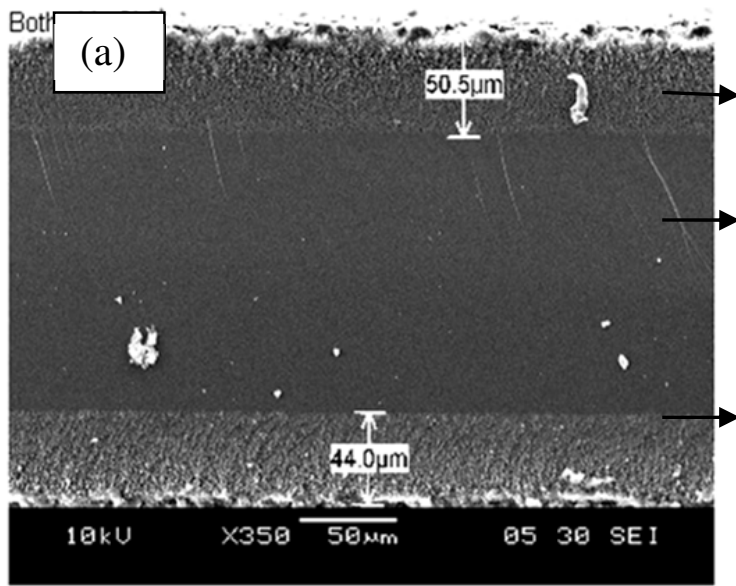

Polished side

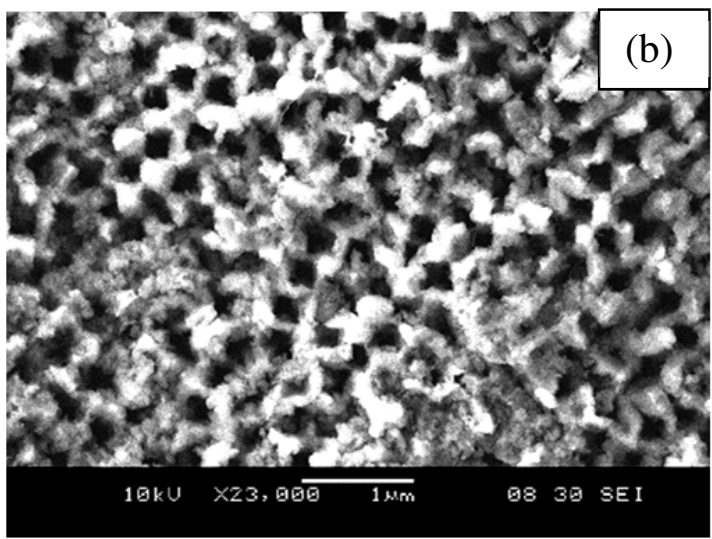

Bulk silicon

Unpolished side

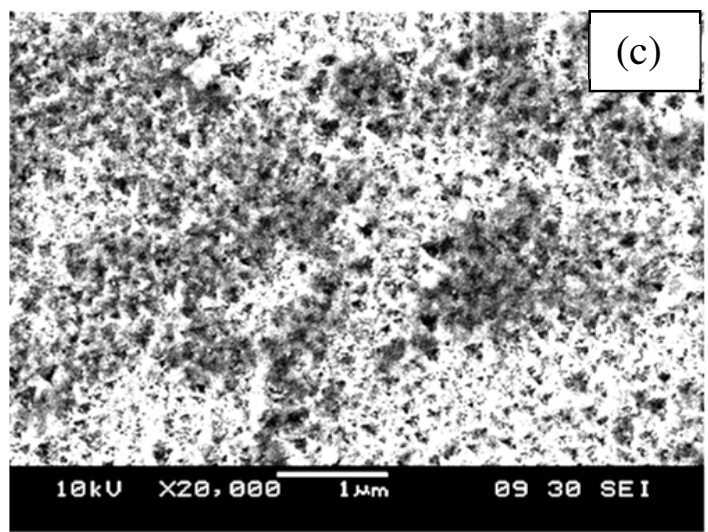

Fig. 9. Cross-sectional SEM images of PS on (a) both sides of the c-Si wafer, (b) on the polished front side c-Si wafer, and (c) on the unpolished backside c-Si wafer 
Figure 10 shows the three-dimensional topographic images of the PS etched surfaces with the pyramidal shape distributed over the entire surface. The pyramidal shape indicates that the increase in surface roughness is because of the effect of the etching parameters on surface characterization. The high degree of roughness of the PS surface implies the possibility of using the porous layer as an ARC because the surface texture reduces light reflection. The scattering in PS is possibly because of the roughness in relation to the thickness of the porous layer [17], whereas the attenuation of the reflectivity is because of scattering and transmission at the porous and bulk interfaces [17, 18]. This parameter is important in enhancing the photoconversion process for solar cells, which confirms that PS can be utilized as an ARC. Meanwhile, the reflection measurement was taken using optical reflectometry.
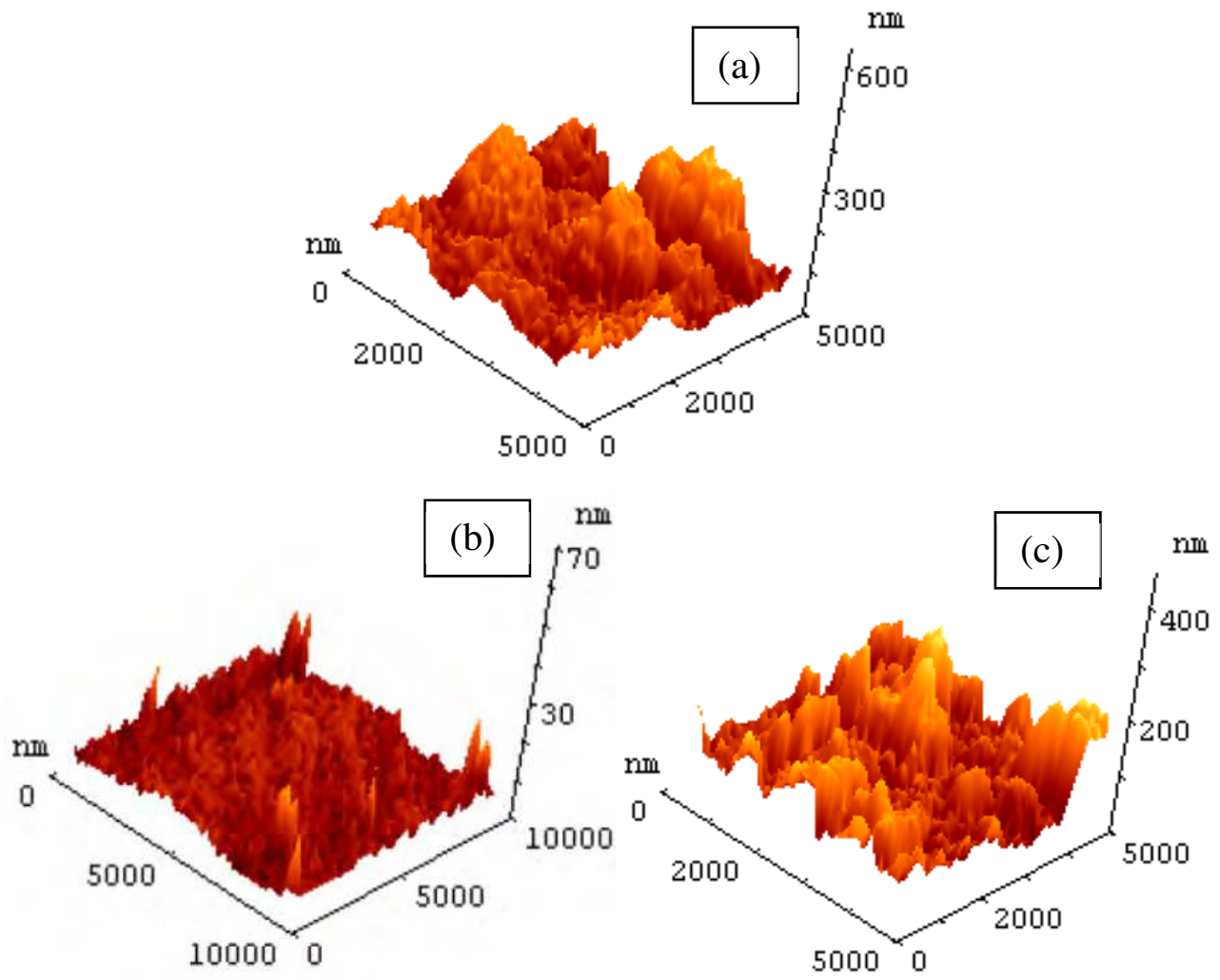

Fig. 10. AFM images of PS (a) as-grown, (b) polished front side, and (c) unpolished back side The results in Fig. 11 demonstrate that the PS that formed on both sides has lower reflectivity value compared with results of other studies [13-15]. These results were confirmed by the absorption spectrum, as shown in Fig. 12. 


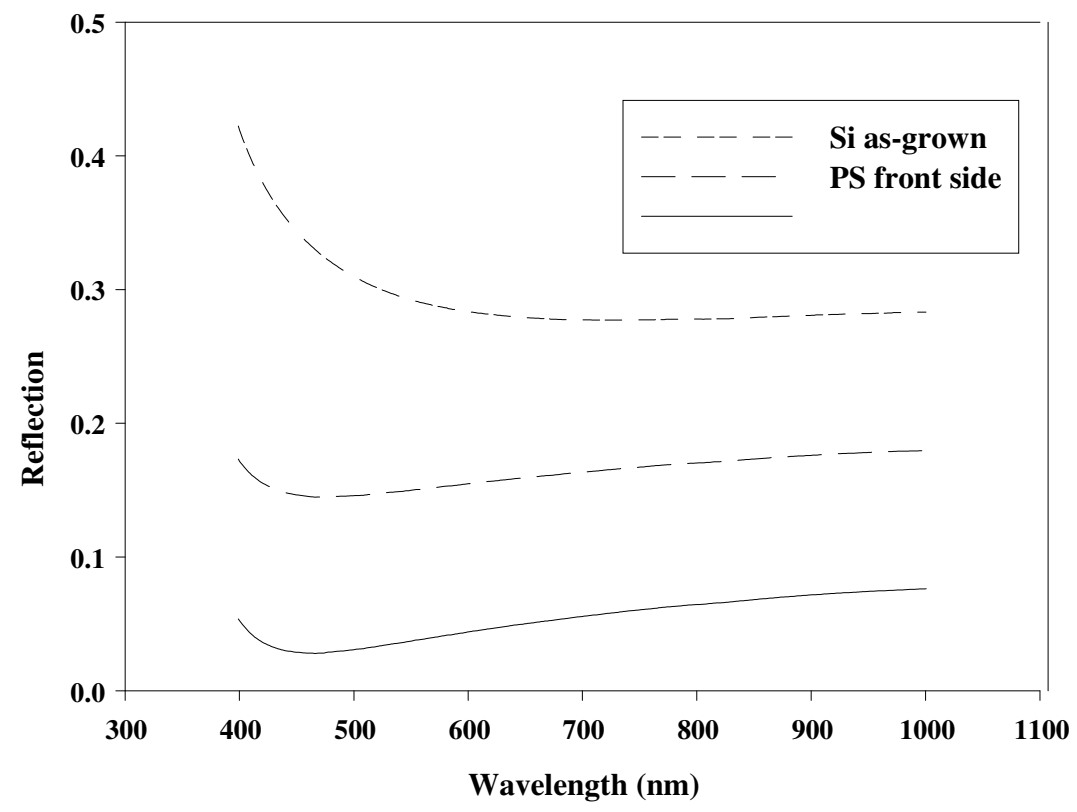

Fig. 11. The reflectance spectra of Si (as grown) and PS of both sides

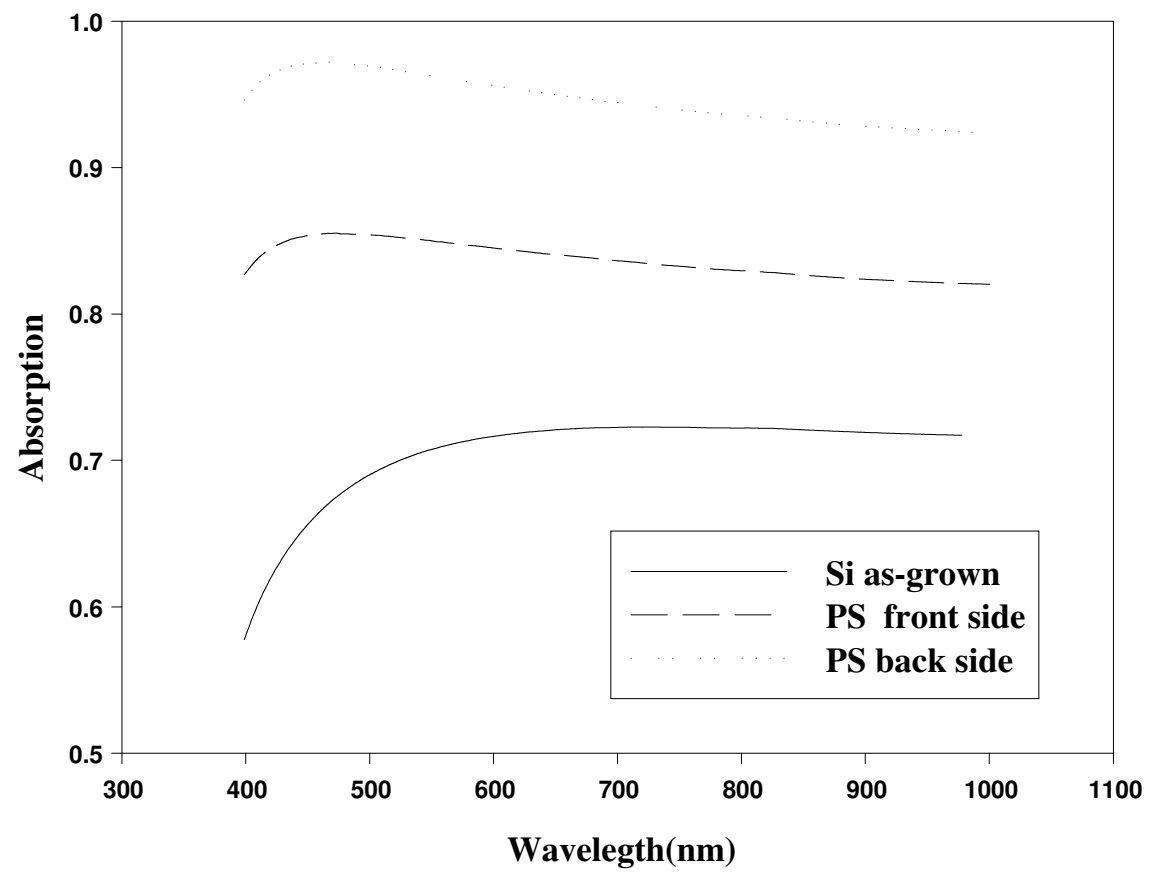

Fig. 12. The reflectance spectra of Si (as grown) and PS of both sides. 
Figures 13 and 14 show the FTIR spectra of the silicon as grown and PS as a function of reflectivity and absorptivity, respectively. The results show an agreement with the results demonstrated in Figs. 4 and 5, indicating that our PS sample has high absorption and low reflection spectra compared with the as-grown sample. This may be attributed to the increase of porosity that leads to an increase in PS density over the surface of the sample.

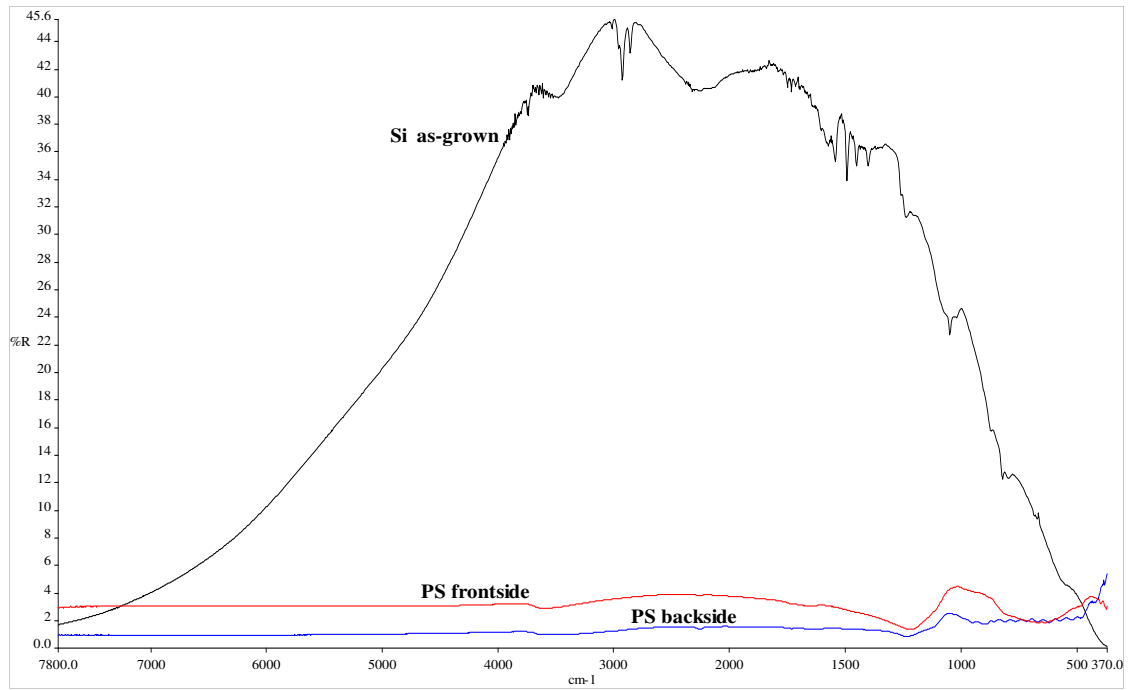

Fig. 13. FTIR reflection spectra of Si (as grown) and PS of both sides

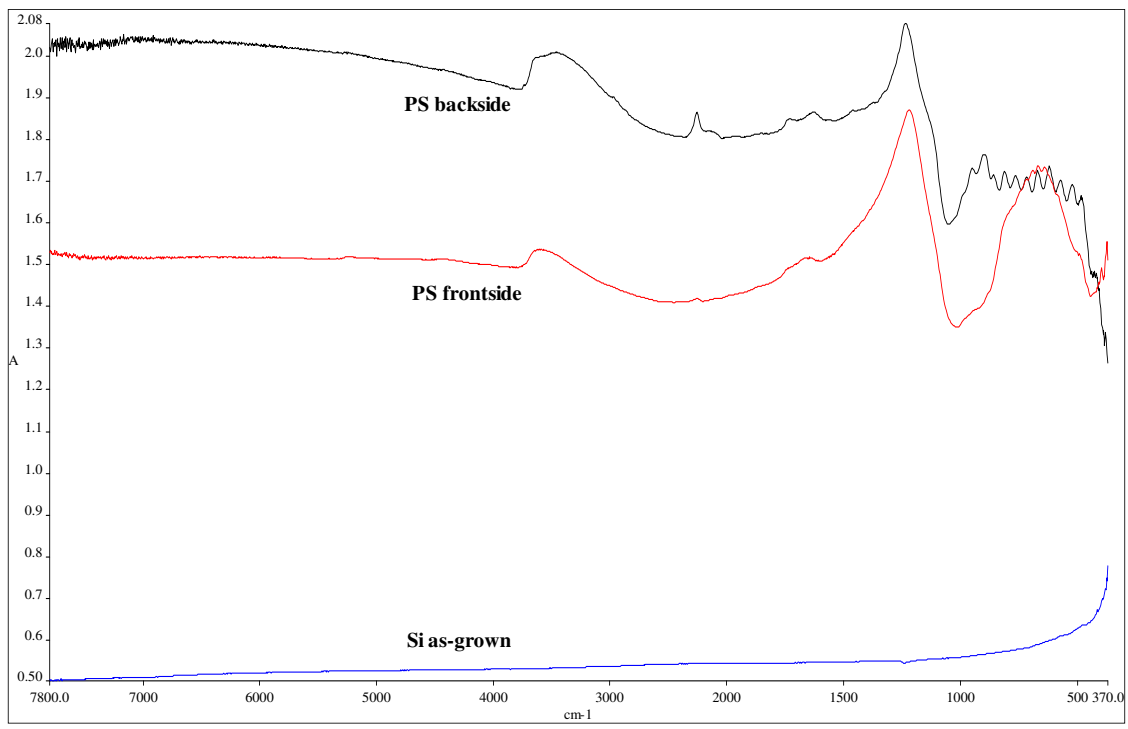

Fig. 14. FTIR absorption spectra of Si (as grown) and PS of both sides 
Figure 15 illustrates the PL spectrum of the PS formed on the unpolished side, revealing a peak at $681.3 \mathrm{~nm}(1.82 \mathrm{eV})$ with FWHM of $330 \mathrm{mV}$. For the PS formed on the front polished side, the peak located at $666.9 \mathrm{~nm}(1.86 \mathrm{eV})$ with a FWHM of approximately $180 \mathrm{mV}$ is obtained. The PS formed on the front polished side has a blue shift luminescence, indicating that the particles are confined into the lower dimension. The energy gaps of the PS increased to 1.82 and 1.86, respectively, and the broadening of the energy gap occurs with a decrease in the crystallite size.

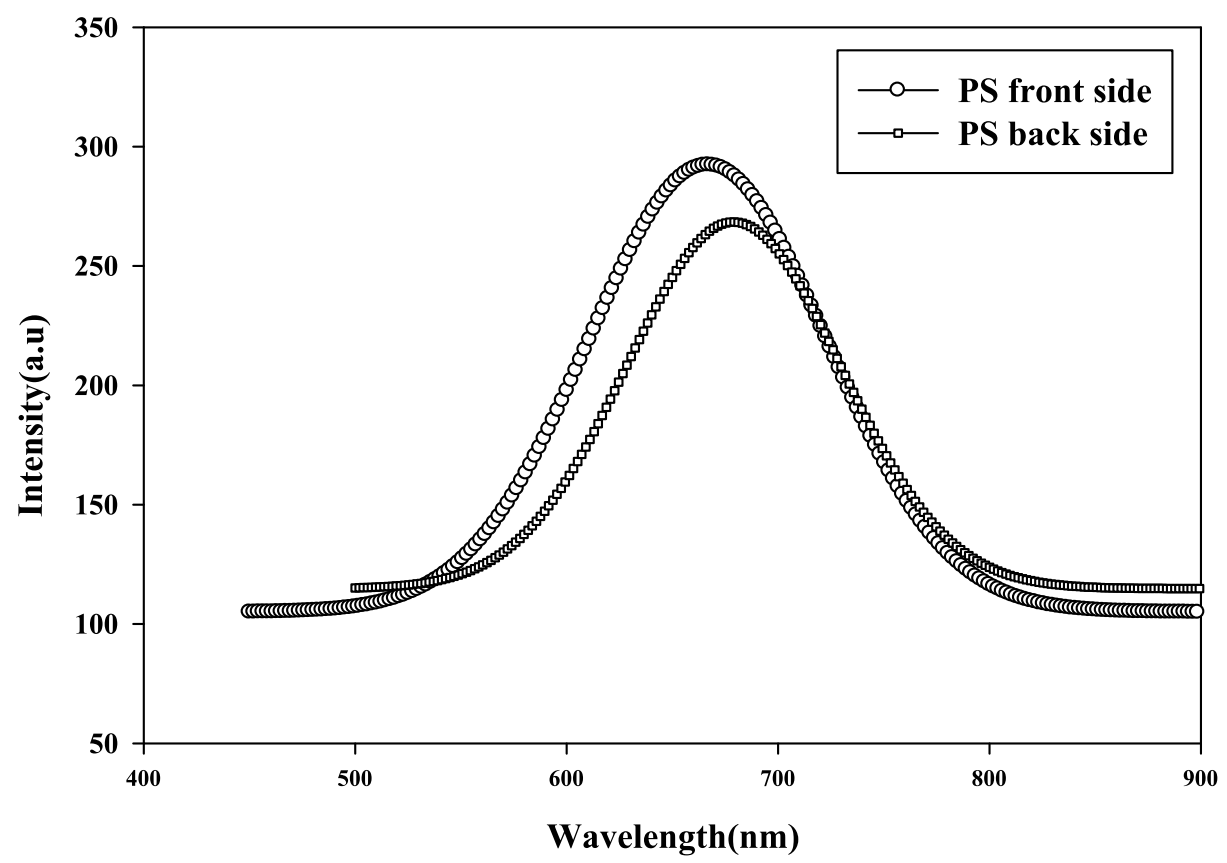

Fig. 15. PL spectra of PS on both sides of the c-Si wafer

The efficiency of the solar cells fabricated with PS formed on both sides of the wafer increased compared with one side of the PS and bulk Si solar cells, respectively, as shown in Fig. 16. This can be attributed to an increase in the open circuit voltage without losing the short circuit current of the solar cells, as shown in Table 2. The porous surface texturing properties are able to enhance and increase the conversion efficiency of Si solar cells, and the resulting efficiency from this procedure is more promising compared with the other solar cells fabricated under similar conditions [19].

\section{Optical properties}

The results in Figs. 4 and 6 are used to calculate the refractive index and optical dielectric constant of Si and PS using the following equation [20]:

$$
n=\frac{1+R^{1 / 2}}{1-R^{1 / 2}}
$$




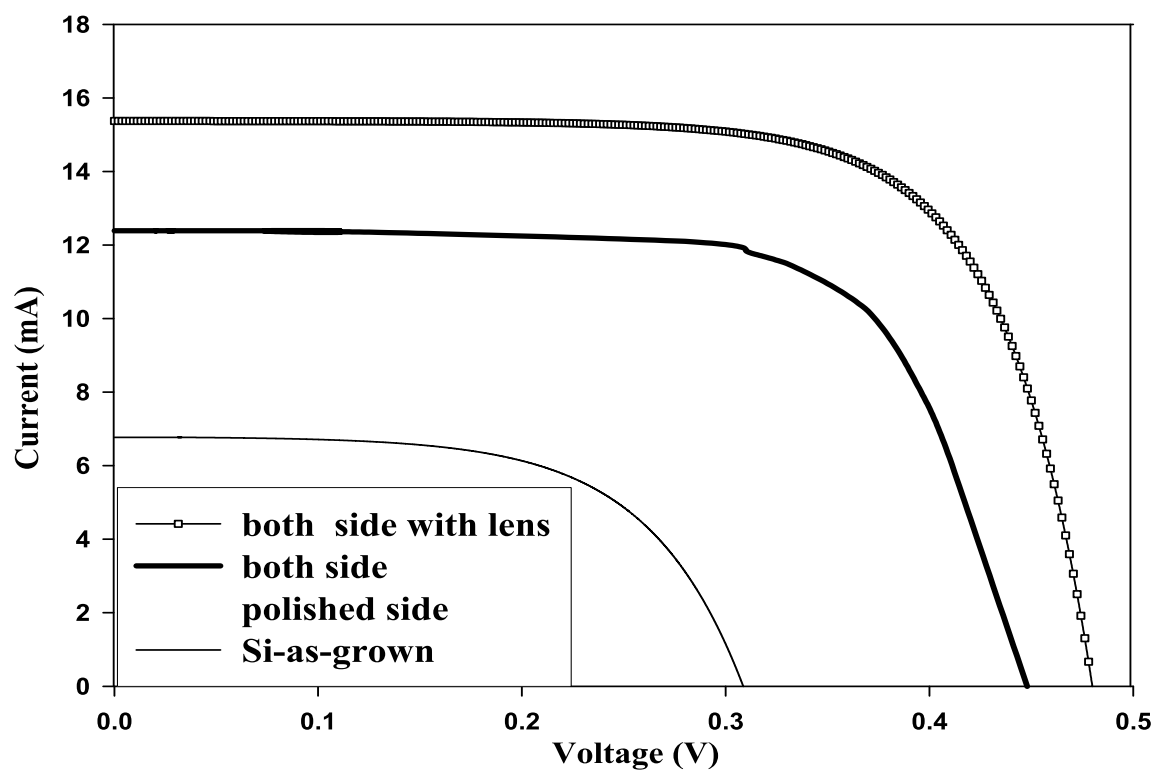

Fig. 16. Current-voltage (IV) characteristics of Si (as grown) and Si of different sides

\begin{tabular}{|l|c|c|c|c|c|c|c|c|}
\hline Samples & $\begin{array}{c}R_{\mathrm{s}} \\
(\Omega)\end{array}$ & $\begin{array}{c}R_{\mathrm{sh}} \\
(\mathrm{k} \Omega)\end{array}$ & $\begin{array}{c}V_{\mathrm{m}} \\
(\mathrm{V})\end{array}$ & $\begin{array}{c}I_{\mathrm{m}} \\
(\mathrm{mA})\end{array}$ & $\begin{array}{c}V_{\mathrm{oc}} \\
(\mathrm{V})\end{array}$ & $\begin{array}{c}I_{\mathrm{sc}} \\
(\mathrm{mA})\end{array}$ & $F F(\%)$ & $\begin{array}{c}\text { Efficiency } \\
(\eta)(\%)\end{array}$ \\
\hline Si as-grown & 70.4 & 2.98 & 0.26 & 6.71 & 0.31 & 6.72 & 83 & 4.34 \\
\hline $\begin{array}{l}\text { PS formed on the } \\
\text { unpolished side }\end{array}$ & 7.14 & 149.8 & 0.41 & 7.24 & 0.43 & 8.83 & 78 & 7.38 \\
\hline $\begin{array}{l}\text { PS formed on both } \\
\text { sides }\end{array}$ & 7.9 & 4.86 & 0.44 & 11.65 & 0.45 & 12.37 & 84 & 12.75 \\
\hline $\begin{array}{l}\text { PS on both sides } \\
\text { with lens }\end{array}$ & 2.81 & 18.77 & 0.41 & 15.12 & 0.49 & 15.5 & 88 & 15.4 \\
\hline
\end{tabular}

Table 2. Investigated series resistance Rs, shunt resistance Rsh, maximum voltage Vm, maximum current Im, open-circuit voltage Voc, short-circuit current Isc, FF, and efficiency (१) of Si and PS

where $\mathrm{R}$ is reflectivity. The refractive index $n$ is an important physical parameter related to microscopic atomic interactions. Theoretically, the two different approaches in viewing this subject are the refractive index related to density and the local polarizability of these entities [21].

In contrast, the crystalline structure represented by a delocalized picture, $n$, is closely related to the energy band structure of the material, complicated quantum mechanical analysis requirements, and the obtained results. Many attempts have been made to relate 
the refractive index and the energy gap Eg through simple relationships [22-27]. However, these relationships of $n$ are independent of temperature and incident photon energy. Here, the various relationships between $n$ and $E_{g}$ are reviewed. Ravindra et al. [27] suggested different relationships between the band gap and the high frequency refractive index and presented a linear form of $n$ as a function of $E_{g}$ :

$$
n=\alpha+\beta E_{g}
$$

where $\alpha=4.048$ and $\beta=-0.62 \mathrm{eV}-1$.

To be inspired by the simple physics of light refraction and dispersion, Herve and Vandamme [28] proposed the empirical relation as

$$
n=\sqrt{1+\left(\frac{A}{E_{g}+B}\right)^{2}},
$$

where $\mathrm{A}=13.6 \mathrm{eV}$ and $\mathrm{B}=3.4 \mathrm{eV}$. Ghosh et al. [29] took a different approach to the problem by considering the band structure and quantum-dielectric formulations of Penn [30] and Van Vechten [31]. Introducing A as the contribution from the valence electrons and B as a constant additive to the lowest band gap Eg, the expression for the high-frequency refractive index is written as

$$
n^{2}-1=\frac{A}{\left(E_{g}+B\right)^{2}},
$$

where $\mathrm{A}=25 \mathrm{Eg}+212, \mathrm{~B}=0.21 \mathrm{Eg}+4.25$, and $(\mathrm{Eg}+\mathrm{B})$ refers to an appropriate average energy gap of the material. Thus, these three models of variation $n$ with energy gap have been calculated. The calculated refractive indices of the end-point compounds are shown in Table 3 , with the optical dielectric constant $\varepsilon_{\infty}$ calculated using $\varepsilon_{\infty}=n^{2}$ [32], which is dependent on the refractive index. In Table 1, the calculated values of $\varepsilon_{\infty}$ using the three models are also investigated. Increasing the porosity percentage from $60 \%$ (front side) to $80 \%$ (back side) uses weight measurements [33] that lead to a decreasing refractive index. As with Ghosh et al. [29],

\begin{tabular}{|c|c|c|}
\hline Samples & $n$ & $\varepsilon_{\infty}$ \\
\hline $\mathrm{Si}$ & $3.35^{\mathrm{a}} 2.91^{\mathrm{b}} 2.89^{\mathrm{c}} \quad 3.46^{\mathrm{d}} 3.46^{\mathrm{e}}$ & $11.22^{\mathrm{a}} \quad 8.46^{\mathrm{b}} \quad 8.35^{\mathrm{c}} 11.97 \mathrm{e}$ \\
\hline PS formed on the unpolished side & $3.17 \mathrm{a} \quad 2.79 \mathrm{~b} \quad 2.77^{\mathrm{c}} 1.8^{\mathrm{e}}$ & $10.04^{\mathrm{a}} \quad 7.78^{\mathrm{b}} \quad 7.67 \mathrm{c} 3.24^{\mathrm{e}}$ \\
\hline $\begin{array}{l}\text { PS formed on the front polished } \\
\text { side }\end{array}$ & $2.94^{\mathrm{a}} \quad 2.68^{\mathrm{b}} \quad 2.66^{\mathrm{c}} 2.38^{\mathrm{e}}$ & $8.64^{\mathrm{a}} \quad 7.18^{\mathrm{b}} \quad 7.07 \mathrm{c} 5.66^{\mathrm{e}}$ \\
\hline
\end{tabular}
this is more appropriate for studying porous silicon solar cell optical properties, which showed lower reflectivity and more absorption as compared to other models.

${ }^{a}$ Ref. [27], bRef. [28], cRef. [29], dRef. [20] exp. eusing Equation (1)

Table 3. Calculated refractive indices for Si and PS using Ravindra et al. [27], Herve and Vandamme [28], and Ghosh et al. [29] models compared with others that corresponds to the optical dielectric constant 


\section{Ionicity character}

The systematic theoretical studies of the electronic structures, optical properties, and charge distributions have already been reported in the literature [34,35]. However, detailed calculations on covalent and ionic bonds have not reached the same degree of a priori completeness as what can be attained in the case of metallic properties. The difficulty in defining the ionicity lies in transforming a qualitative or verbal concept into a quantitative, mathematical formula. Several empirical approaches have been developed [36] in yielding analytic results that can be used for exploring the trends in materials properties. In many applications, these empirical approaches do not give highly accurate results for each specific material; however, they still can be very useful. The stimulating assumption of Phillips [36] concerning the relationship of the macroscopic (dielectric constant, structure) and the microscopic (band gap, covalent, and atomic charge densities) characteristics of a covalent crystal is based essentially on the isotropic model of a covalent semiconductor, whereas Christensen et al. [37] performed self-consistent calculations and used model potentials derived from a realistic GaAs potential where additional external potentials were added to the anion and cation sites. However, in general, the ionicities found by Christensen et al. tend to be somewhat larger than those found by Phillips. In addition, Garcia and Cohen [38] achieved the mapping of the ionicity scale by an unambiguous procedure based on the measure of the asymmetry of the first principle valence charge distribution [39]. As for the Christensen scale, their results were somewhat larger than those of the Phillips scale. Zaoui et al. [40] established an empirical formula for the calculation of ionicity based on the measure of the asymmetry of the total valence charge density, and their results are in agreement with those of the Phillips scale. In the present work, the ionicity, fi, was calculated using different formulas [41], and the theory yielded formulas with three attractive features. Only the energy gap $\mathrm{Eg} \Gamma \mathrm{X}$ was required as the input, the computation of fi itself was trivial, and the accuracy of the results reached that of ab initio calculations. This option is attractive because it considers the hypothetical structure and simulation of experimental conditions that are difficult to achieve in the laboratory (e.g., very high pressure). The goal of the current study is to understand how qualitative concepts, such as ionicity, can be related to energy gap $\mathrm{Eg} \Gamma \mathrm{X}$ with respect to the nearest-neighbor distance, $\mathrm{d}$, cohesive energy, $\mathrm{E}_{\mathrm{coh}}$, and refractive index, $\mathrm{n}_{0}$. Our calculations are based on the energy gap $\mathrm{Eg} \Gamma \mathrm{X}$ reported previously [34,42-45], and the energy gap that follows chemical trends is described by a homopolar energy gap. Numerous attempts have been made to face the differences between energy levels. Empirical pseudopotential methods based on optical spectra encountered the same problems using an elaborate (but not necessarily more accurate) study based on one-electron atomic or crystal potential. As mentioned earlier, d, $\mathrm{E}_{\mathrm{coh}}$, and $\mathrm{n}_{0}$ have been reported elsewhere for $\mathrm{Si}$ and PS. One reason for presenting these data in the present work is that the validity of our calculations, in principle, is not restricted in space. Thus, they will no doubt prove valuable for future work in this field. An important observation for studying ionicity, $f_{i}$, is the distinguished difference between the values of the energy gaps of the semiconductors, $\mathrm{Eg} \Gamma \mathrm{X}$, as seen in Table 2; hence, the energy gaps $\mathrm{Eg} \Gamma \mathrm{X}$ are predominantly dependent on fi . The differences between the energy gaps Egrx have led us to consider these models, and the bases of our models are the energy gaps, $\mathrm{Eg} \Gamma \mathrm{X}$, as seen in Table 4. The fitting of these data gives the following empirical formulas [41]: 


$$
\begin{aligned}
& f_{i}=\lambda\left(\frac{\left(d / E_{g \Gamma X}\right)}{4}\right) \\
& f_{i}=\lambda\left(\frac{\left(E_{c o h} / E_{g \Gamma X}\right)}{2}\right) \\
& f_{i}=\lambda\left(\frac{\left(n_{0} / E_{g \Gamma X}\right)}{4}\right)
\end{aligned}
$$

where $\mathrm{Eg} \Gamma \mathrm{X}$ is the energy gap in $(\mathrm{eV}), \mathrm{d}$ the nearest-neighbor distance in $(\AA), \mathrm{E}_{\text {coh }}$ the cohesive energy in $(\mathrm{eV}), \mathrm{n}_{0}$ the refractive index, and $\lambda$ is a parameter separating the strongly ionic materials from the weakly ionic ones. Thus, $\lambda=0,1$, and 6 are for the Groups IV, III-V, and II-VI semiconductors, respectively. The calculated ionicity values compared with those of Phillips [36], Christensen et al. [37], Garcia and Cohen [38], and Zaoui et al. [40] are given in Table 2. We may conclude that the present ionicities, which were calculated differently than in the definition of Phillips, are in good agreement with the empirical ionicity values, and exhibit the same chemical trends as those found in the values derived from the Phillips theory or those of Christensen et al. [37], Garcia and Cohen [38], and Zaoui et al. [40] (Table 2).

\begin{tabular}{|l|c|c|c|c|c|c|c|c|c|}
\hline Samples & $d^{\mathrm{a}}(\AA)$ & $\begin{array}{c}E_{\mathrm{coh}} \mathrm{b} \\
(\mathrm{eV})\end{array}$ & $n_{0}$ & $\begin{array}{c}f_{\mathrm{i}} \\
\mathrm{cal} .\end{array}$ & $f_{\mathrm{i}} \mathrm{g}$ & $f_{\mathrm{i}} \mathrm{h}$ & $f_{\mathrm{i}} \mathrm{i}$ & $f_{\mathrm{i}}$ & $\begin{array}{c}E_{\mathrm{g}} \Gamma \mathrm{X} \\
(\mathrm{eV})\end{array}$ \\
\hline $\mathrm{Si}$ & 2.35 & 2.32 & $3.673^{\mathrm{c}}$ & $0 \mathrm{e} 0^{\mathrm{f}}$ & 0 & 0 & 0 & 0 & 1.1 \\
\hline $\begin{array}{l}\text { PS formed } \\
\text { on the } \\
\text { unpolished } \\
\text { side }\end{array}$ & & $2.77 \mathrm{~d}$ & 0 & 0 & 0 & 0 & 0 & 1.82 \\
\hline $\begin{array}{l}\text { PS formed } \\
\text { on the front } \\
\text { polished } \\
\text { side }\end{array}$ & & $2.66^{\mathrm{d}}$ & 0 & 0 & 0 & 0 & 0 & 1.86 \\
\hline
\end{tabular}

aRef. [46], bRef. [47], cRef. [48], dRef. [29], eRef. [41]: Formulas (5-7), ,Ref. [49], gRef. [36], hRef. [37], iRef. [38], iRef. [40]

Table 4. Calculated ionicity character for Si and PS along with those of Phillips [36], Christensen et al. [37], Garcia and Cohen [38], Zaoui et al. [40], and Al-Douri et al. [41] 
The difficulty involved with such calculations resides with the lack of a theoretical framework that can describe the physical properties of crystals. Generally speaking, any definition of ionicity is likely to be imperfect. Although we may argue that, for many of these compounds, the empirically calculated differences are of the same order as the differences between the reported measured values, these trends are still expected to be real [47]. The unchanged ionicity characters of bulk Si and PS are noticed. In conclusion, the empirical models obtained for the ionicity give results in good agreement with the results of other scales, which in turn demonstrate the validity of our models to predict some other physical properties of such compounds.

\section{Material stiffness}

The bulk modulus is known as a reflectance of the crucial material stiffness in different industries. Many authors [50-55] have made various efforts to explore the thermodynamic properties of solids, particularly in examining the thermodynamic properties such as the inter-atomic separation and the bulk modulus of solids with different approximations and best-fit relations [52-55]. Computing the important number of structural and electronic properties of solids with great accuracy has now become possible, even though the ab initio calculations are complex and require significant effort. Therefore, additional empirical approaches have been developed [36,47] to compute properties of materials. In many cases, the empirical methods offer the advantage of applicability to a broad class of materials and to illustrate trends. In many applications, these empirical approaches do not provide highly accurate results for each specific material; however, they are still very useful. Cohen [46] established an empirical formula for calculating bulk modulus B0 based on the nearestneighbor distance, and the result is in agreement with the experimental values. Lam et al. [56] derived an analytical expression for the bulk modulus from the total energy that gives similar numerical results even though this expression is different in structure from the empirical formula. Furthermore, they obtained an analytical expression for the pressure derivative $\mathrm{B} 0$ of the bulk modulus. Meanwhile, our group [57] used a concept based on the energy gap along $\Gamma-X$ and transition pressure to establish an empirical formula for the calculation of the bulk modulus, the results of which are in good agreement with the experimental data and other calculations. In the present work, we have established an empirical formula for the calculation of bulk modulus B0 of a specific class of materials, and the theory yielded a formula with three attractive features. Apparently, only the energy gap along $\Gamma-\mathrm{X}$ and transition pressure are required as an input, and the computation of $\mathrm{B} 0$ in itself is trivial. The consideration of the hypothetical structure and simulation of the experimental conditions are required to make practical use of this formula.

The aim of the present study is to determine how a qualitative concept, such as the bulk modulus, can be related to the energy gap. We [57] obtained a simple formula for the bulk moduli of diamond and zinc-blende solids using scaling arguments for the relevant bonding and volume. The dominant effect in these materials has been argued to be the degree of covalence, as characterized by the homopolar gap, Eh of Phillips, [36] and the gap along $\Gamma-X$ [57]. Our calculation is based upon the energy gap along $\Gamma-X$ which has been reported previously [42-45], and the energy gaps that follow chemical trends are described by homopolar and heteropolar energy gaps. Empirical pseudopotential methods based on 
optical spectra encounter the same problems using an elaborate (but not necessarily more accurate) study based on one electron atomic or crystal potential. One of the earliest approaches [58] involved in correlating the transition pressure with the optical band gap [e.g., the band gap for a-Sn is zero and the pressure for a transition to $\beta$-Sn is vanishingly small, whereas for Si with a band gap of $1 \mathrm{eV}$, the pressure for the same transition is approximately $12.5 \mathrm{GPa}$ (125 kbar)]. A more recent effort is from Van Vechten [59], who used the dielectric theory of Phillips [36] to scale the zinc-blende to $\beta$-Sn transition with the ionic and covalent components of the chemical bond. The theory is a considerable improvement with respect to earlier efforts, but is limited to the zinc-blende to $\beta$-Sn transition. As mentioned, $\mathrm{Eg} \Gamma \mathrm{X}$ and $\mathrm{Pt}$ have been reported elsewhere for several semiconducting compounds. One reason for presenting these data in the current work is that the validity of our calculations is not restricted in computed space. Thus, the data is bound prove valuable for future work in this field.

An important reason for studying $\mathrm{B} 0$ is the observation of clear differences between the energy gap along $\Gamma-\mathrm{X}$ in going from the group IV, III-V, and II-VI semiconductors in Table 4, where one can see the effect of the increasing covalence. As covalence increases, the pseudopotential becomes more attractive and pulls the charge more toward the core region, thereby reducing the number of electrons available for bonding. The modulus generally increases with the increasing covalence, but not as quickly as predicted by the uniform density term. Hence, the energy gaps are predominantly dependent on B0. A likely origin for the above result is the increase of ionicity and the loss of covalence. The effect of ionicity reduces the amount of bonding charge and the bulk modulus. This picture is essentially consistent with the present results; hence, the ionic contribution to B0 is of the order $40 \%-50 \%$ smaller. The differences between the energy gaps have led us to consider this model.

The basis of our model is the energy gap as seen in Table 4 . The fitting of these data gives the following empirical formula [57]:

$$
B_{0}=(30+\lambda 10)\left[\left(P_{t}^{1 / 2} / E_{g \Gamma X}\right) / 3\right]
$$

where $\operatorname{Eg} \Gamma \mathrm{X}$ is the energy gap along $\Gamma-\mathrm{X}$ (in $\mathrm{eV}$ ), $\mathrm{Pt}$ is the transition pressure (in GPa " $k b a r ")$, and $\lambda$ is an empirical parameter that accounts for the effect of ionicity; $\lambda=0 ; 1,5$ for group IV, III-V, and II-VI semiconductors, respectively. In Table 5, the calculated bulk modulus values are compared with the experimental values and the results of Cohen [46], Lam et al. [56], and Al-Douri et al. [57].

We may conclude that the present bulk moduli calculated in a different way than in the definition of Cohen are in good agreement with the experimental values. Furthermore, the moduli exhibit the same chemical trends as those found for the values derived from the experimental values, as seen in Table 5. The results of our calculations are in reasonable agreement with the results of Cohen [46] and the experiments of Lam et al. [56], and are more accurate than in our previous work [57]. As mentioned previously, an approach [57] that elucidates the correlation of the transition pressure with the optical band gap exists. This procedure gives a rough correlation and fails badly for some materials such as AlSb that have a larger band gap than $\mathrm{Si}$ but have a lower transition pressure [64]. From the above empirical formula, a correlation is evident between the transition pressure and B0 
[e.g., the $\mathrm{B}_{0}$ for $\mathrm{Si}$ is $100.7 \mathrm{GPa}$ and the pressure for the transition to $\beta$-Sn is $12.5 \mathrm{GPa}$ (125 kbar), whereas for $\mathrm{GaSb}, \mathrm{B} 0$ is $55.5 \mathrm{GPa}$ and the transition pressure to $\beta$-Sn is $7.65 \mathrm{GPa}$ (76.5 kbar)]. This correlation fails for a compound such as ZnS that has a smaller value of B0 than Si but has a larger transition pressure. In conclusion, the empirical model obtained for the bulk modulus gives results that are in good overall agreement with previous results.

\begin{tabular}{|c|c|c|c|c|c|c|c|}
\hline Samples & $\begin{array}{l}B_{0} \text { cal. } \\
(\mathrm{GPa})\end{array}$ & $\begin{array}{c}B_{0} \text { exp. }^{\mathrm{b}} \\
(\mathrm{GPa})\end{array}$ & $\begin{array}{c}B_{0}[46] \\
(\mathrm{GPa})\end{array}$ & $\begin{array}{c}B_{0}[56] \\
(\mathrm{GPa})\end{array}$ & $\begin{array}{c}B_{0}[57] \\
(\mathrm{GPa})\end{array}$ & $B_{0}(\mathrm{GPa})$ & $\begin{array}{c}P_{\mathrm{t}} \mathrm{e} \\
(\mathrm{GPa})\end{array}$ \\
\hline $\mathrm{Si}$ & $\begin{array}{l}101^{a^{\prime}} \\
91.5^{a^{\prime \prime}} \\
100^{a^{\prime \prime \prime}}\end{array}$ & 98 & 98 & 100 & 92 & $\begin{array}{c}92^{c} \\
93.6^{d}\end{array}$ & 12.5 \\
\hline $\begin{array}{l}\text { PS formed } \\
\text { on the } \\
\text { unpolished } \\
\text { side }\end{array}$ & $\begin{array}{c}61.4^{a^{\prime}} \\
150.7^{a^{\prime \prime}} \\
165^{a^{\prime \prime \prime}}\end{array}$ & & & & & & \\
\hline $\begin{array}{l}\text { PS formed } \\
\text { on the front } \\
\text { polished } \\
\text { side }\end{array}$ & $\begin{array}{c}60.1^{\mathrm{a}^{\prime}} \\
148.5^{\mathrm{a}^{\prime \prime}} \\
169^{\mathrm{a}^{\prime \prime \prime}}\end{array}$ & & & & & & \\
\hline
\end{tabular}

a'Ref. [57], a"'Ref. [60], a'”'Ref. [61], bRef. [46], cRef. [62], dRef. [63], eRef. [64]

Table 5. Calculated bulk modulus for Si and PS together with experimental values, and the results of Cohen [46], Lam et al. [56], Al-Douri et al. [57] values, and others [43,44]

\section{Conclusions}

PS formed on the unpolished backside of the c-Si wafer showed an increase in surface roughness compared with one formed on the polished front side. The high degree of roughness along with the presence of the nanocrystal layer implies that the surface used as an ARC, which can reduce the reflection of light and increase light trapping on a wide wavelength range. This parameter is important in enhancing the photo conversion process for solar cell devices. PS formed on both sides has low reflectivity value. Fabricated solar cells show that the conversion efficiency is $15.4 \%$ compared with the unetched sample and other results $[13,15]$. The results of the refractive index and optical dielectric constant of Si and PS are investigated. The results of Ghosh et al. proved the appropriate for studying porous silicon solar cell optical properties. The mentioned models of ionicity in our study indicated a good accordance with other scales .other side, the empirical model obtained for the bulk modulus gives results that are in good overall agreement with previous results. 


\section{Acknowledgement}

Support from FRGS grant and Universiti Sains Malaysia aregratefully acknowledged.

\section{References}

[1] V.M. Aroutiounia, K.S.h. Martirosyana, S. Hovhannisyana, G. Soukiassianb, J. Contemp. Phys. 43 (2008) 72.

[2] Wisam J Aziz, Asmat Ramizy, K. Ibrahim, Khalid Omar, Z. Hassan, Journal of Optoelectronic and Advanced Materials (JOAM), Vol. 11, No. 11, p. 1632 - 1636, Nov. (2009)

[3] Asmiet Ramizy, Wisam J Aziz, Z. Hassan, Khalid Omar and K. Ibrahim, Microelectronics International, Vol. 27, No. 2, pp. 117-120, 2010.

[4] Wisam J. Aziz, Asmiet Ramizy, K. Ibrahim, Z. Hassan, Khalid Omar, In Press, Corrected Proof, Available online 17 January 2011,OPTIK, Int. J. Light Electron Opt.

[5] Asmiet Ramizy, Wisam J. Aziz, Z. Hassan, Khalid. Omar and K. Ibrahim, In Press, Corrected Proof, Available online 9 March 2011, OPTIK,

[6] Asmiet Ramizy, Z. Hassan, Khalid Omar, Y. Al-Douri, M. A. Mahdi. Applied Surface Science, Applied Surface Science, Vol. 257, Iss. 14, (2011) pp. 6112-6117.

[7] Asmiet Ramizy, Wisam J. Aziz, Z. Hassan, Khalid Omar, and K. Ibrahim, Accepted, Materials Science-Poland.

[8] D.-H. Oha, T.W. Kim, W.J. Chob, K.K. D, J. Ceram. Process. Res. 9 (2008) 57.

[9] G. Barillaro, A. Nannini, F. Pieri, J. Electrochem. Soc. C 180 (2002) 149.

[10] J. Guobin, S. Winfried, A. Tzanimir, K. Martin, J. Mater. Sci. Mater. Electron. 19 (2008) S9.

[11] F. Yan, X. Bao, T. Gao, Solid State Commun. 91 (1994) 341.

[12] M. Yamaguchi, Super-high efficiency III-V tandem and multijunction cells, in: M.D. Archer, R. Hill (Eds.), Clean Electricity from Photovoltaics, Super-High Effi- ciency III-V Tandem and Multijunction Cells, Imperial College Press, London, 2001, p. 347.

[13] M. Ben Rabha, B. Bessaïs, Solar Energy 84 (2010) 486.

[14] S. Yae, T. Kobayashi, T. Kawagishi, N. Fukumuro, H. Matsuda, Solar Energy 80 (2006) 701.

[15] R. Brendel, Solar Energy 77 (2004) 969.

[16] Adam. A, Susan. S, and Raphael. T, J Vac Sci Technol., B 146 (1996) 3431

[17] G. Lerondel, R. Romestain, in: L. Canham (Ed.), Reflection and Light Scat tering in Porous Silicon, Properties of porous silicon, INSPEC, UK, 1997, p. 241.

[18] Asmiet Ramizy, Z. Hassan, K. Omar, J. Mater. Sci. Elec, (First available online).

[19] J. A. Wisam, Ramizy.Asmiet, I. K, O. Khalid, and H. Z, Journal of Optoelectronic and Advance Materials 11 (2009) pp.1632

[20] M. A. Mahdi, S. J. Kasem, J. J. Hassen, A. A. Swadi, S. K. J.Al-Ani, Int. J.Nanoelectronics and Materials 2 (2009) 163

[21] N. M. Balzaretti, J. A. H. da Jornada, Solid State Commun. 99 (1996) 943

[22] T. S. Moss, Proc. Phys. Soc. B 63 (1950) 167 
[23] V. P. Gupta, N. M. Ravindra, Phys. Stat. Sol. B 100 (1980) 715

[24] Y. Al-Douri, Mater. Chem. Phys. 82 (2003) 49

[25] Y. Al-Douri, Y. P. Feng, A. C. H. Huan, Solid State Commun. 148 (2008) 521

[26] P. Herve, L. K. J. Vandamme, Infrared Phys. Technol. 35 (1993) 609

[27] N. M. Ravindra, S. Auluck, V. K. Srivastava, Phys. Stat. Sol. (b) 93 (1979) K155

[28] P. J. L. Herve, L. K. J. Vandamme, J. Appl. Phys. 77 (1995) 5476

[29] D. K. Ghosh, L. K. Samanta, G. C. Bhar, Infrared Phys. 24 (1984) 34

[30] D. R. Penn, Phys. Rev. 128 (1962) 2093

[31] J. A. Van Vechten, Phys. Rev. 182 (1969) 891

[32] G. A. Samara, Phys. Rev. B 27 (1983) 3494

[33] Halimaoui A. 1997, 'Porous silicon formation by anodization', in: L. Canham (Ed.), Properties of porous silicon, INSPEC, UK (1997) 18

[34] J.R. Chelikowsky, M.L. Cohen, Phys. Rev. B14 (1976) 556

[35] C.S. Wang, B.M. Klein, Phys. Rev. B24 (1981) 3393

[36] J.C. Phillips, Bonds and Bands in Semiconductors, Academic Press, San Diego, 1973

[37] N.E. Christensen, S. Stapathy, Z. Pawlowska, Phys. Rev. B36 (1987) 1032

[38] A. Garcia, M.L. Cohen, Phys. Rev. B47 (1993) 4215

[39] A. Garcia, M.L. Cohen, Phys. Rev. B47 (1993) 4221

[40] A. Zaoui, M. Ferhat, B. Khelifa, J.P. Dufour, H. Aourag, Phys. Stat. Sol. (b) 185 (1994) 163

[41] Y. Al-Douri, H. Abid, H. Aourag, Mater. Chem. Phys. 65 (2000) 117

[42] I.M. Tsidilkovski, Band Structure of Semiconductors, Pergamon, Oxford, 1982

[43] K. Strossner, S. Ves, Chul Koo Kim, M. Cardona, Phys. Rev. B33 (1986) 4044

[44] C. Albert, A. Joullié, A.M. Joullié, C. Ance, Phys. Rev. B27 (1984) 4946

[45] R.G. Humphreys, V. Rossler, M. Cardona, Phys. Rev. B18 (1978) 5590

[46] M.L. Cohen, Phys. Rev. B32 (1985) 7988

[47] W.A. Harison, Electronic Structure and the Properties of Solids, General Publishing Company, Toronto, 1989

[48] Landolt-Bornstein, Numerical Data and Functional Realtionships in Science and Technology - Crystal and Solid State Physics, vol. 22, Springer, Berlin, 1987

[49] Y. Al-Douri, J. Eng. Res. Edu. 4 (2007) 81

[50] A.M. Sherry, M. Kumar, J. Phys. Chem. Solids 52 (1991) 1145

[51] J.L. Tallon, J. Phys. Chem. Solids 41 (1980) 837

[52] M. Kumar, S.P. Upadhyaya, Phys. Stat. Sol. B 181 (1994) 55

[53] M. Kumar, Physica B 205 (1995) 175

[54] R.K. Pandey, J. Phys. Chem. Solids 59 (1998) 1157.

[55] Qing He, Zu-Tong Yan, Phys. Stat. Sol. B 223 (2001) 767.

[56] P.K. Lam, M.L. Cohen, G. Martinez, Phys. Rev. B 35 (1987) 9190.

[57] Y. Al-Douri, H. Abid, H. Aourag, Physica B 322 (2002) 179.

[58] J.C. Jamieson, Science 139 (1963) 845.

[59] J.A. Van Vechten, Phys. Rev. B 7 (1973) 1479.

[60] Y. Al-Douri, H. Abid, H. Aourag, Mater. Chem. Phys. 87 (2004) 14.

[61] Y. Al-Douri, Res. Lett. Mater. Sci. 57 (2007) 143.

[62] Y. Al-Douri, H. Abid, H. Aourag, Physica B 305 (2001) 186 
[63] Y. Al-Douri, H. Abid, H. Aourag, Mater. Lett. 59 (2005) 2032

[64] J.R. Chelikowsky, Phys. Rev. B 35 (1987) 1174. 


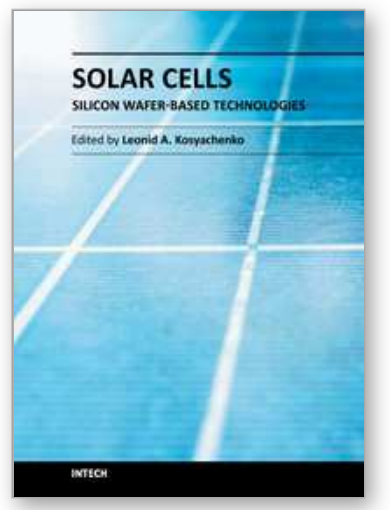

\author{
Solar Cells - Silicon Wafer-Based Technologies \\ Edited by Prof. Leonid A. Kosyachenko
}

ISBN 978-953-307-747-5

Hard cover, 364 pages

Publisher InTech

Published online 02, November, 2011

Published in print edition November, 2011

The third book of four-volume edition of 'Solar Cells' is devoted to solar cells based on silicon wafers, i.e., the main material used in today's photovoltaics. The volume includes the chapters that present new results of research aimed to improve efficiency, to reduce consumption of materials and to lower cost of wafer-based silicon solar cells as well as new methods of research and testing of the devices. Light trapping design in c-Si and $\mathrm{mc}$-Si solar cells, solar-energy conversion as a function of the geometric-concentration factor, design criteria for spacecraft solar arrays are considered in several chapters. A system for the micrometric characterization of solar cells, for identifying the electrical parameters of PV solar generators, a new model for extracting the physical parameters of solar cells, LBIC method for characterization of solar cells, non-idealities in the I-V characteristic of the PV generators are discussed in other chapters of the volume.

\title{
How to reference
}

In order to correctly reference this scholarly work, feel free to copy and paste the following:

Asmiet Ramizy, Y. Al-Douri, Khalid Omar and Z. Hassan (2011). Optical Insights into Enhancement of Solar Cell Performance Based on Porous Silicon Surfaces, Solar Cells - Silicon Wafer-Based Technologies, Prof. Leonid A. Kosyachenko (Ed.), ISBN: 978-953-307-747-5, InTech, Available from:

http://www.intechopen.com/books/solar-cells-silicon-wafer-based-technologies/optical-insights-intoenhancement-of-solar-cell-performance-based-on-porous-silicon-surfaces

\section{INTECH}

open science | open minds

\author{
InTech Europe \\ University Campus STeP Ri \\ Slavka Krautzeka 83/A \\ 51000 Rijeka, Croatia \\ Phone: +385 (51) 770447 \\ Fax: +385 (51) 686166 \\ www.intechopen.com
}

\author{
InTech China \\ Unit 405, Office Block, Hotel Equatorial Shanghai \\ No.65, Yan An Road (West), Shanghai, 200040, China \\ 中国上海市延安西路65号上海国际贵都大饭店办公楼 405 单元 \\ Phone: +86-21-62489820 \\ Fax: $+86-21-62489821$
}


(C) 2011 The Author(s). Licensee IntechOpen. This is an open access article distributed under the terms of the Creative Commons Attribution 3.0 License, which permits unrestricted use, distribution, and reproduction in any medium, provided the original work is properly cited. 